\title{
Green synthesis of nanoparticle and its application on cotton fabric using Sterculia foetida fruit shell extract
}

\begin{abstract}
Sterculia foetida fruit shell was used for the green synthesis of silver nanoparticles. Optimized reduction of silver ion $\left(\mathrm{Ag}^{+}\right)$to metallic silver nanoparticles $\left(\mathrm{Ag}^{\circ}\right)$ was carried out at room temperature for $16 \mathrm{hr}$. The reduced silver nanoparticles were characterized by UV-visible spectroscopy, particle size analyzer, FTIR and SEM analysis of treated cotton fabric not only showed superb coloration but also proven to be very good in antibacterial and ultraviolet protection properties even after ten washes.
\end{abstract}

Keywords: Sterculia foetida fruit shell, Silver nanoparticles, cotton, dyeing, antibacterial, UV protection

\author{
Volume 6 Issue 6 - 2020 \\ Pintu Pandit, ${ }^{1,2}$ MD Teli,, ${ }^{2}$ Gayatri T Nadathur, ${ }^{2}$ \\ Saptarshi Maiti, ${ }^{2}$ Kunal Singha,' Subhankar \\ Maity ${ }^{3}$ \\ 'Department of Textile Design, National Institute of Fashion \\ Technology, India \\ ${ }^{2}$ Department of Fibres and Textile Processing Technology, \\ Institute of Chemical Technology, India \\ ${ }^{3}$ Department of Textile Technology, Uttar Pradesh Textile \\ Technology Institute, India
} National Institute of Fashion Technology, Mithapur Farms, Patna-80000I, India, Email pintupanditict@gmail.com, pintu.pandit@nift.ac.in

Received:September 02, 2020 | Published: December II, 2020

\section{Introduction}

Biosynthesis of nanoparticles by microorganisms is a green and eco-friendly technology. The synthesis of nanoparticles could be extracellular in line with the positioning of nanoparticles. ${ }^{1}$ For generating nanoparticles with plant extracts, the extract is combined with a solution of the metal salt at different temperatures and response times. The reducing agents associated comprise the other water-soluble plant metabolites (e.g., alkaloids, phenolic substances, and terpenoids) and also co-enzymes. ${ }^{2}$ Extracts of a wide array of plant species have been successfully utilized in making nanoparticles. The green synthesis procedure is a simple, economical and environmentally friendly system of the synthesis of metal nanoparticles compare to physical and chemical processes. ${ }^{3}$ Synthesis approaches of nanoparticles are categorized into two different methods, top-down and bottom-up. ${ }^{4}$ In the top-down strategy, thin films or bulk substances are all scaled down to create nanodevices with other lithographic methods, e.g., grinding, milling, and thermal/laser ablation. The bottom-up approach utilizes small and easy building blocks (atoms, molecules, nanoparticles, etc.) that will self-assemble into larger, more intricate structures. ${ }^{5}$ In the bottom to top approach, nanoparticles can be synthesized using biological and chemical methods from the self-assembly of atoms to new nuclei, which grow into a particle of the nanoscale. Eco-friendly processes such as the synthesis of nanoparticles have gained momentum nowadays ${ }^{6}$ with nanotechnology likely to have a significant influence in different areas. ${ }^{7,8}$ Many techniques, such as thermal decomposition, microwave-assisted, etc., have been researched for its synthesis of silver nanoparticles. Biological procedures for synthesizing silver nanoparticles ${ }^{9-11}$ are considered a valuable alternative to chemical or physical methods. In the present work, dried Sterculia foetida fruit shell extract (FSE) has been taken and use for the synthesis of this silver nanoparticle. ${ }^{12-14}$
Sterculia foetida open sections look a lot like woody, valentineheart-shaped bowls. Alcoholic leaves extract also played a substantial part in anti-inflammatory and central nervous depressant action. ${ }^{15,16}$ There's been a lot of attention focused on producing medications and goods, which are organic, and its seed oil plays an essential role in this regard. Thus, the present study was done to know more about the phytochemical properties of Sterculia foetida fruit shells that are accountable for the medicinal and functional properties. ${ }^{17-20}$

\section{Material and methods}

\section{Material}

The substance used for experimental work is prepared for dyeing cotton cloth $(110 \mathrm{GSM})$. Precursors silver nitrate $\left(\mathrm{AgNO}_{3}\right)$ is among the analytical grade employed in this experimentation acquired from Merck, India.

\section{Preparation of fruit shell extracts}

The fresh and washed fruit shell of the required amount was cut into small bits and transferred to $500 \mathrm{ml}$ round bottom flask containing $100 \mathrm{ml}$ of distilled water. The refluxing procedure was utilized to get the colored solution/dye, which was used for dyeing. Then the temperature of this reaction system has been increased to $100^{\circ} \mathrm{C}$ and kept for 60 minutes. Ultimately, the extract was filtered using nylon fabric and centrifuged for $15 \mathrm{~min}$ at $4000 \mathrm{rpm}$ two times to find undissolved particles to be settled. The supernatant solution was used for dyeing in the laboratory rota dyer machine (Rossari Labtech).

\section{Green synthesis of silver nanoparticles (H-AgNPs)}

Silver nanoparticles were synthesized using fruit shell extracts of Sterculia foetida fruit shell extract (H-AgNPs). 1mM Silver nitrate solution of volume $80 \mathrm{ml}$ was taken in a reaction vessel. 
Then the required amount of fruit shell extract was added and mixed homogeneously on a magnetic stirrer at room temperature. Optimization of reaction time and concentration of fruit shell extract required to synthesize nanoparticles were carried out separately.

\section{Dyeing procedure}

Dyeing was carried out in a beaker at room temperature, and a laboratory rota dyer machine was used with programmable time and temperature control. The required amount of dye was taken according to the dyeing shade on the weight of fabric (o.w.f.). Dyeing trials were carried out both at neutral $\mathrm{pH}$ and alkaline $\mathrm{pH}$. In contrast, the dyeing conditions were room temperature for $60 \mathrm{~min}$ and exhaust dyeing at $90^{\circ} \mathrm{C}$ for $60 \mathrm{~min}$ in the rota dyeing machine (Figure 1).

\section{Particle size analysis}

The average particle size of nanoparticles was measured by the laser diffraction method using Shimadzu SALD-7500 analyzer at room temperature.

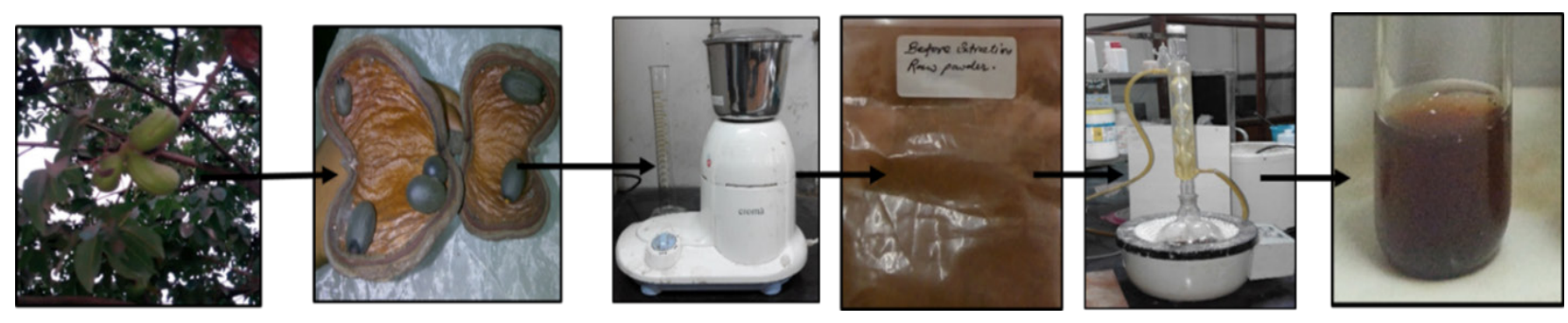

Figure I Extraction procedure of raw material to natural dye.

\section{UV-visible spectroscopy analysis}

The UV-vis spectra of nanoparticles were recorded at room temperature using Shimadzu UV-1800 Spectrophotometer. The absorption spectra of fruit shell extract synthesized nanoparticles were recorded in the range of $290 \mathrm{~nm}$ to $800 \mathrm{~nm}$, with distilled water as the reference.

\section{Colour characteristics analysis}

Cotton fabric treated with nanoparticles showed a coloration effect and samples were evaluated for the depth of color and colour difference by reflectance method using $10^{\circ}$ observers with D65 illuminant. The reflectance of nanoparticle-treated samples was measured on Rayscan Spectra scan 5100+ equipped with reflectance accessories

\section{UV protective properties of the fabric}

UV protection characteristics of fabrics were determined by measuring ultra-violet protection factor (UPF) rating, according to the Australian and New Zealand (AS/NZS 4399) standard by using UVvis spectrophotometer (UV-2600, Shimadzu, Japan).

\section{Antibacterial properties}

The antibacterial efficacy of a compound will vary as per its presence in the solution or on the textile substrate. The quantitative assessment of antibacterial activity exhibited on the finished cotton fabric was carried out by AATCC Test 100-2004.

\section{SEM-EDS analysis}

The untreated and treated sample were analyzed utilizing Field Emission Gun-Scanning Electron Microscope (FEG-SEM, TESCAN). Specimen size of $5 \times 5 \mathrm{~mm}^{2}$ was shot and the conductive agent employed was sputter-coated for its 600 s length. The beam voltage of $10 \mathrm{kV}, 2000 \mathrm{X}$ magnification and $6 \mathrm{~mm}$ working space for examining the sample had been utilized.

\section{Results and discussions}

\section{Green synthesis of silver nanoparticles using fruits shell extract}

In a typical synthesis process, fruit shell extract causes the reduction of silver ions $\left(\mathrm{Ag}^{+}\right)$in an aqueous solution. It leads to the formation of metallic silver $\left(\mathrm{Ag}^{\circ}\right)$, which is further nucleated to form silver nanoparticles. The nanoparticle size increases or decreases on nucleation. ${ }^{21}$ Thus, to synthesize particles having a minimum size, synthesis parameters such as extract concentration and reaction time were optimized with silver nitrate concentration $(1 \mathrm{mM})$ constant. The color change is noted by virtual observation in Sterculia foetida fruit shell extract incubated with an aqueous sol of $1 \mathrm{mM} \mathrm{AgNO}_{3}$. The color changed from the extract color yellowish-brown due to the reduction of silver ions, thus exhibiting the formation of silver nanoparticles, as shown in Figure 2.

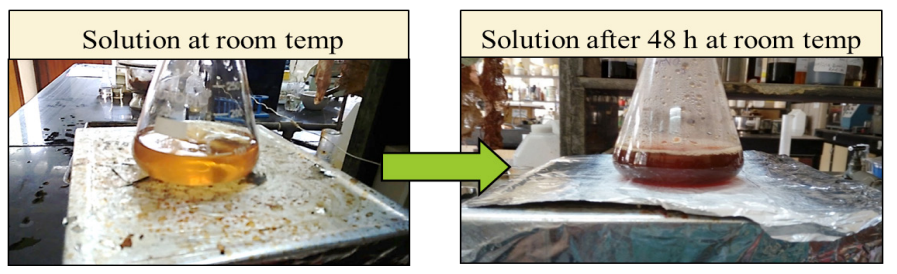

Figure 2 Colour change of the fruit shell extract after $48 \mathrm{~h}$.

\section{Particle size analysis of reduced silver nitrate concerning the time}

The results indicate that with increasing the concentration of the extract, particle size increased. This is attributed to increasing the rate of reaction, which caused higher nucleation of metallic silver leading to an increase in particle size. Hence, $10 \mathrm{ml}$ of extract concentration was taken as optimum for the synthesis of silver nanoparticles using Sterculia foetida fruit shell extract. Using a concentration of $10 \mathrm{ml}$, the time of reaction was varied. The particle size decreased significantly with an increase in time. Larger particles are formed during longer reaction times due to the agglomeration of particles. Hence, to get smaller particles the time of reaction was optimized at 16 hours. The particle size distribution graph of the sample at a different time is shown in Figure 3 and Table 1.

The reaction for the synthesis of fruit shell extract-AgNPs was also carried out at $50 \mathrm{ml}$ of extract concentration with the time of response $16 \mathrm{~h}$ at $\mathrm{pH} 7$ and $\mathrm{pH} 10$. The particle size distribution graph of the optimized sample at $50 \mathrm{ml}$ concentration of FSE is shown in Figure 4 and Table 2. The distribution graph showed that the particles were uniform in size with an average particle size of $51 \mathrm{~nm}$ in $\mathrm{pH} 7$ and $57 \mathrm{~nm}$ in $\mathrm{pH} 10$ for $16 \mathrm{~h}$. 

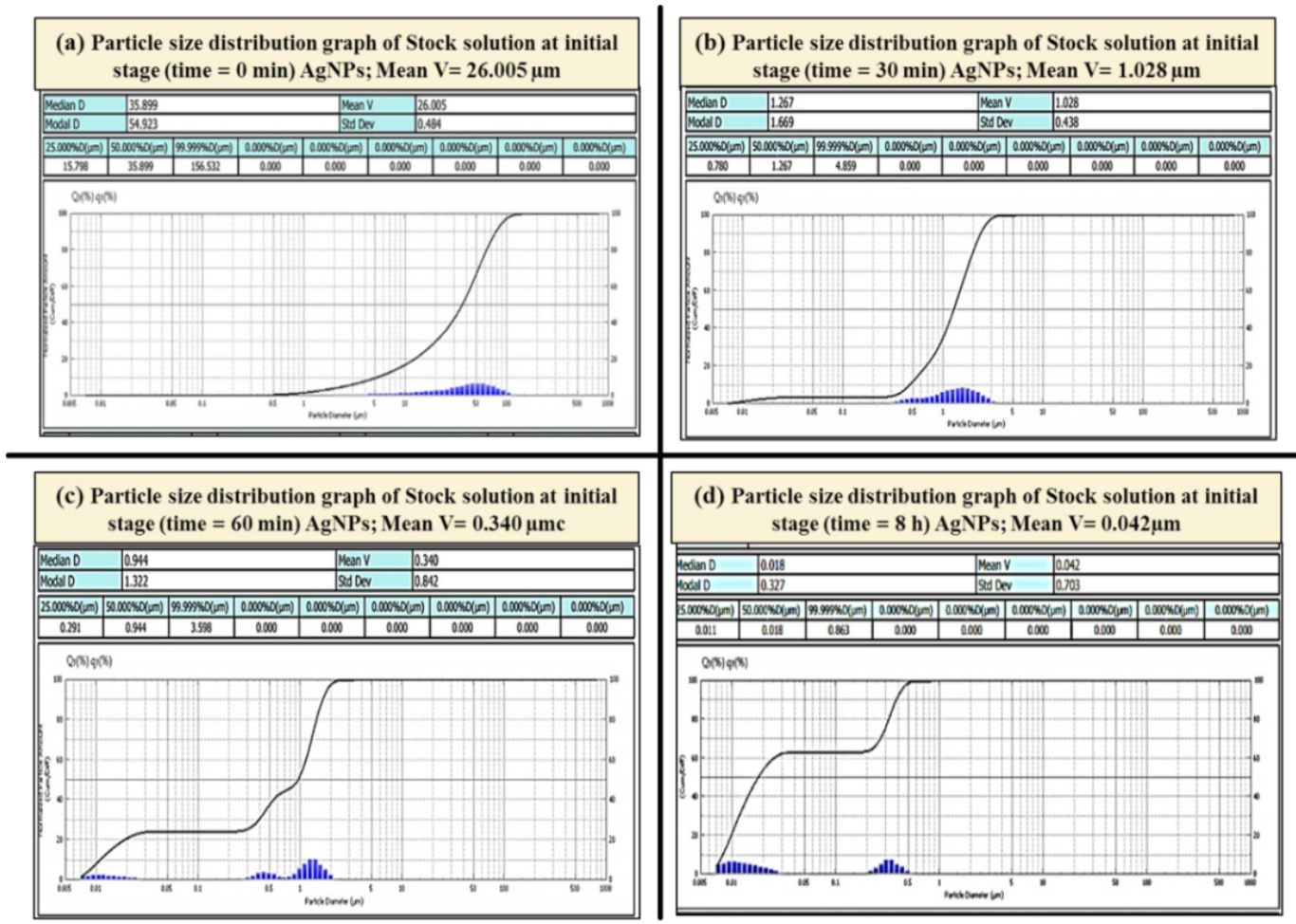

(e) Particle size distribution graph of Stock solution at initial stage (time = 16 h) AgNPs; Mean V= 0.029 $\mu \mathrm{m}$

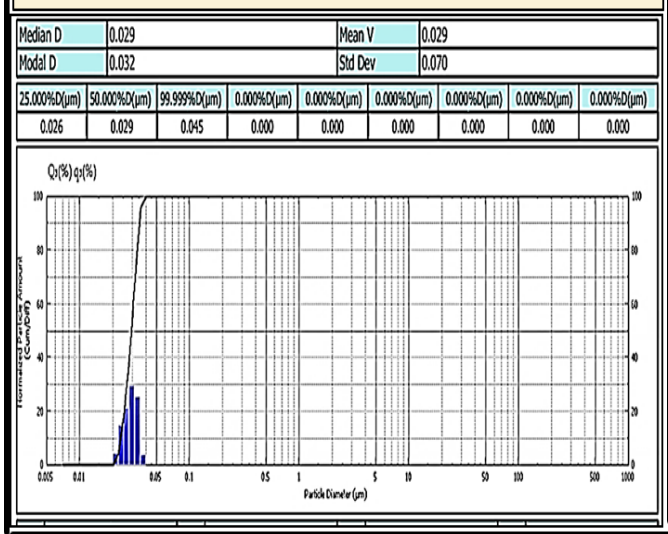

(f) Particle size distribution graph of Stock solution at initial

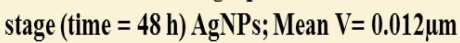

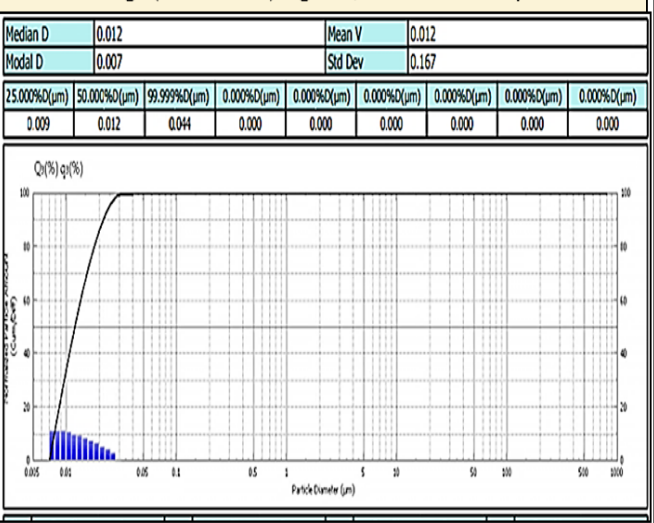

Figure 3 Particle size analysis of silver in fruit shell extract at (a) $0 \min$ (b) $30 \mathrm{~min}$ (c) $60 \mathrm{~min}$ (d) $8 \mathrm{~h} \mathrm{(e)} 16 \mathrm{~h}$ and (f) $48 \mathrm{~h}$.

Table I Effect of different parameters on the particle size of silver nanoparticles synthesized using Sterculia foetida fruit shell extract (FSE)

\begin{tabular}{|c|c|c|c|c|}
\hline \multirow{2}{*}{ Code } & \multirow{2}{*}{ Extract conc. FSE (ml) } & \multirow{2}{*}{ Time (min) } & Mean particle size & \multirow{2}{*}{ Change in $(\mathrm{pH})$} \\
\hline & & & ( $\mu$ meter) & \\
\hline (a) & 10 & 0 & 26.005 & $5.9-6.5$ \\
\hline (b) & 10 & 30 & 1.028 & 6.5 \\
\hline (c) & 10 & 60 & 0.34 & 6.7 \\
\hline (d) & 10 & $480(8 \mathrm{~h})$ & $0.042(42 \mathrm{~nm})$ & 6.8 \\
\hline (e) & 10 & $960(16 h)$ & $0.029(29 \mathrm{~nm})$ & 7 \\
\hline$(f)$ & 10 & $2880(48 h)$ & $0.012(12 \mathrm{~nm})$ & 7 \\
\hline
\end{tabular}

Citation: Pandit P, Teli MD, Nadathur GT, et al. Green synthesis of nanoparticle and its application on cotton fabric using Sterculia foetida fruit shell extract.J Textile Eng Fashion Technol. 2020;6(6):257-265. DOI: 10.15406/jteft.2020.06.00259 

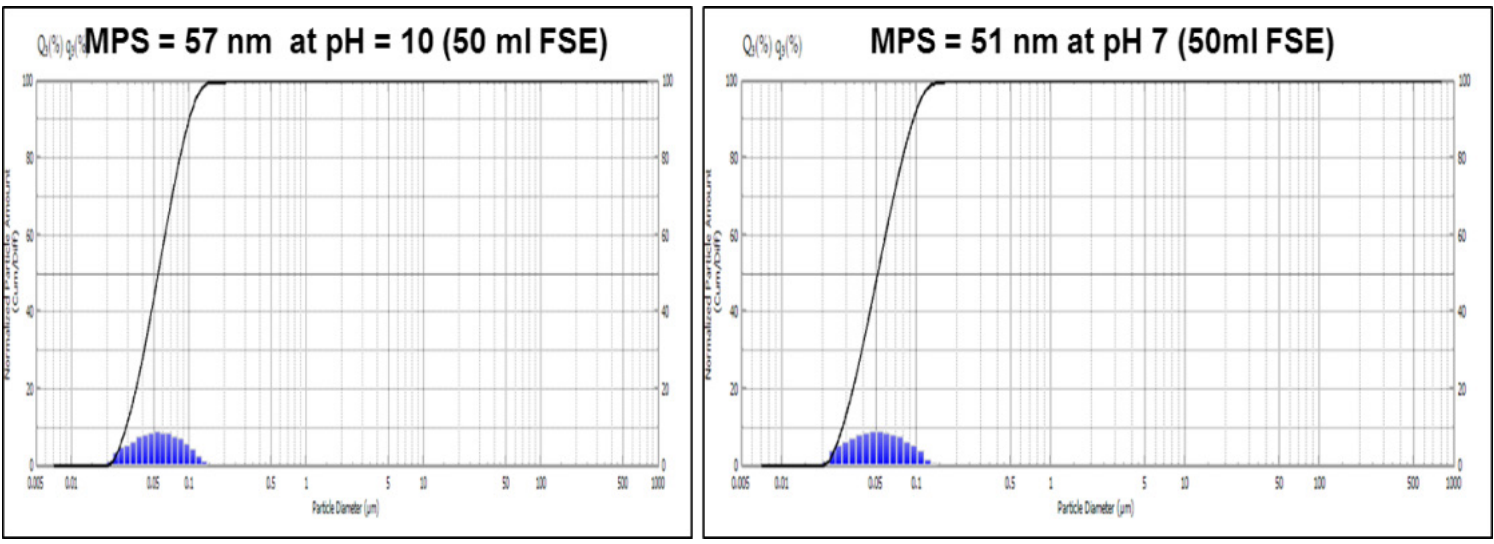

Figure 4 Particle size analysis of $50 \mathrm{ml}$ of fruit shell extract at different $\mathrm{pH}$ for $16 \mathrm{~h}$.

Table 2 Mean particle size for optimized process parameters at different $\mathrm{pH}$

\begin{tabular}{llll}
\hline Extract Conc. $(\mathbf{m l})$ & Time (h) & Mean particle size $(\mathbf{n m})$ & $\mathbf{p H}$ \\
\hline 10 & 16 & 29 & 7 \\
10 & 16 & 63 & 10 \\
50 & 16 & 51 & 7 \\
50 & 16 & 57 & 10 \\
\hline
\end{tabular}

Mean particle size results have been reported in Table 2 for $16 \mathrm{~h}$ and further work for dyeing and finishing effect on cotton fabric has been carried out at two different concentrations $10 \mathrm{ml}$ and $50 \mathrm{ml} \mathrm{FSE}$ in two different $\mathrm{pH} 7$ and $\mathrm{pH} 10$ at room temperature and $90^{\circ} \mathrm{C}$ for $1 \mathrm{~h}$.

\section{UV visible absorption studies of silver nanoparticles}

Measurement on UV-visible spectra is a technique to confirm the formation of metal nanoparticles. ${ }^{22}$ An absorption band was found for the silver nanoparticles in the range of $390-450 \mathrm{~nm}$, generated by surface plasmon vibrations of conducting electrons of silver. The UV-visible spectra of a colloidal solution of optimized $10 \%$ fruit shell extract concentration for $16 \mathrm{~h}$ and $50 \%$ fruit shell extract concentration for $16 \mathrm{~h}$ AgNPs are shown in Figure 5 and it showed a strong absorption band of $430 \mathrm{~nm}$, which is somewhat close to the reported work (Figure 6).

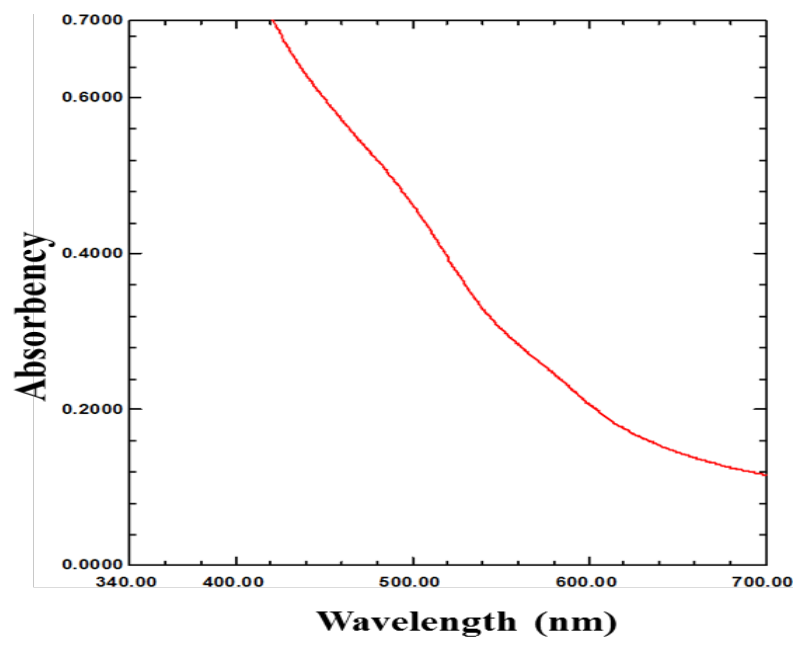

Figure 5 UV-visible spectra of Sterculia foetida fruit shell extract solution.

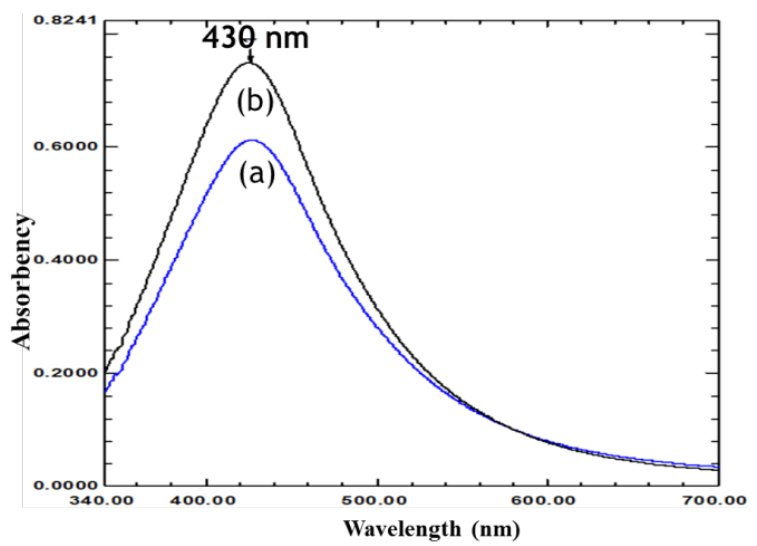

Figure 6 UV-visible spectra of (a) $10 \%$ extract concentration for $16 \mathrm{~h}$ and (b) $50 \%$ extract concentration for $16 \mathrm{~h}$.

Relating these data with particle size, the absorption bands showed a redshift from 404 to $430 \mathrm{~nm}$ due to an increase in particle size. ${ }^{23}$ Absorption bands showed a single, sharp and intense peak suggesting the formation of mono-dispersed and spherical shaped nanoparticles. The color changed from the extracted color to yellowish-brown due to the reduction of silver ions, thus exhibiting the formation of silver nanoparticles. Fruit shell extract without silver nitrate solution did not show any color change. The color change of extract was seen after 16 at room temperature. Thus, the absorption spectrum at different wavelengths ranging from $340-700 \mathrm{~nm}$ revealed a peak of $\lambda \max$ at $430 \mathrm{~nm}$ confirmed reduced silver nanoparticles.

\section{Dyeing of cotton fabric}

Dyeing of FSE synthesized silver nanoparticles of cotton fabric at room temperature for $1 \mathrm{~h}$ : Coloration imparted for treated cotton fabric using optimized synthesized silver nanoparticles for $10 \%$ and 
$50 \%$ fruit shell extract was analyzed for the depth of shade concerning $\mathrm{K} / \mathrm{S}$ and CIE Lab Parameters $\mathrm{L}^{*}, \mathrm{a}^{*}$, and $\mathrm{b}^{*}$ when applied at room temperature for $1 \mathrm{~h}$ and results are mentioned in Table 3 . It is found from Table 3 that coloration is imparted at room temperature for $1 \mathrm{~h}$.
However, colour fading obtained were more after 5 washes. The highest colour retained $(\mathrm{K} / \mathrm{S}=0.8156, \mathrm{pH} 10)$ in the case of fabric treated with silver nanoparticles synthesized using $50 \%$ Sterculia foetida as shown in Table 4.

Table 3 Dyeing of cotton fabric at room temperature for Ih before washing

\begin{tabular}{llllll}
\hline Sample & $\mathbf{p H}$ & $\mathbf{L}^{*}$ & $\mathbf{a}^{*}$ & $\mathbf{b}^{*}$ & $\mathbf{K} / \mathbf{S}$ \\
\hline Cotton treated with 10\% FSE-AgNPs & 7 & 58.383 & 9.58 & 18.29 & 0.963 \\
Cotton treated with 10\% FSE-AgNPs & 10 & 75.156 & 4.74 & 16.933 & 2.015 \\
Cotton treated with 50\% FSE-AgNPs & 7 & 58.359 & 6.64 & $17 . .701$ & 1.116 \\
Cotton treated with 50\% FSE-AgNPs & 10 & 56.217 & 6.67 & $14.78 \mathrm{I}$ & 2.813
\end{tabular}

Table 4 Dyeing of cotton fabric at room temperature for Ih after 5 washing

\begin{tabular}{llllll}
\hline Sample & $\mathbf{p H}$ & $\mathbf{L}^{*}$ & $\mathbf{a}^{*}$ & $\mathbf{b}^{*}$ & $\mathbf{K} / \mathbf{S}$ \\
\hline Cotton treated with 10\% FSE-AgNPs & 7 & 70.216 & 3.63 & 10.379 & 0.6335 \\
Cotton treated with 10\% FSE-AgNPs & 10 & 69.959 & 3.24 & 10.235 & 0.5992 \\
Cotton treated with 50\% FSE-AgNPs & 7 & 74.176 & 7.85 & 18.533 & 0.7791 \\
Cotton treated with 50\% FSE-AgNPs & 10 & 73.669 & 7.83 & 18.162 & 0.8156 \\
\hline
\end{tabular}

Assessment of fastness properties of the dyed cotton fabric (room temperature)

The fastness ratings of cotton fabric dyed with silver nanoparticles at different concentrations are presented in Table 5. Before washes, it was found that washing fastness of the dyed cotton fabrics using Sterculia foetida fruit shell was moderate to good for cotton fabric. Light fastness was of the grade good to moderate for cotton fabric. However, after 10 washes overall fastness properties were found to be reduced.

Table 5 Fastness properties of dyed cotton fabric at room temperature for Ih

\begin{tabular}{|c|c|c|c|c|c|c|c|c|c|}
\hline \multirow{3}{*}{ Dye conc., \% owf } & \multirow{3}{*}{$\mathrm{pH}$} & \multicolumn{4}{|c|}{ Initial (before washes) } & \multicolumn{4}{|c|}{ After 10 washes } \\
\hline & & \multirow{2}{*}{$\begin{array}{l}\text { Wash } \\
\text { fastness }\end{array}$} & \multirow{2}{*}{$\begin{array}{l}\text { Light } \\
\text { fastness }\end{array}$} & \multicolumn{2}{|c|}{ Rubbing fastness } & \multirow{2}{*}{$\begin{array}{l}\text { Wash } \\
\text { fastness }\end{array}$} & \multirow{2}{*}{$\begin{array}{l}\text { Light } \\
\text { fastness }\end{array}$} & \multicolumn{2}{|c|}{ Rubbing fastness } \\
\hline & & & & Dry & Wet & & & Dry & Wet \\
\hline $\begin{array}{l}\text { Cotton treated with } \\
10 \% \text { FSE-AgNPs }\end{array}$ & 7 & 3 & $5-6$ & 5 & 5 & 2 & 5 & 5 & $4-5$ \\
\hline $\begin{array}{l}\text { Cotton treated with } \\
10 \% \text { FSE-AgNPs }\end{array}$ & 10 & 3 & $5-6$ & 5 & 5 & 2 & 5 & 5 & $4-5$ \\
\hline $\begin{array}{l}\text { Cotton treated with } \\
50 \% \text { FSE-AgNPs }\end{array}$ & 7 & $3-4$ & $4-5$ & 5 & 5 & $2-3$ & 4 & 5 & 4 \\
\hline $\begin{array}{l}\text { Cotton treated with } \\
50 \% \text { FSE-AgNPs }\end{array}$ & 10 & $3-4$ & $4-5$ & 5 & $4-5$ & $2-3$ & 4 & 5 & 4 \\
\hline
\end{tabular}

\section{Dyeing of FSE synthesized silver nanoparticles of Cotton fabric at $90^{\circ} \mathrm{C}$ for Ih}

Coloration imparted for treated cotton fabric using optimized synthesized silver nanoparticles for $10 \%$ and $50 \%$ fruit shell extract was analyzed for the depth of shade concerning K/S and CIE Lab Parameters $\mathrm{L}^{*}, \mathrm{a}^{*}$, and $\mathrm{b}^{*}$ for treatment at $90^{\circ} \mathrm{C}$ for $1 \mathrm{~h}$ and results are mentioned in Table 6. It was found from Table 6 that coloration is imparted at $90^{\circ} \mathrm{C}$ for $1 \mathrm{~h}$ and color decreases slightly after 5 washes. The highest color was obtained $(\mathrm{K} / \mathrm{S}=2.1734, \mathrm{pH} 10)$ in the case of fabric treated with silver nanoparticles synthesized using $50 \%$ Sterculia foetida extract. The result showed that there were slight changes in $\mathrm{K} / \mathrm{S}$ values even after 5 washes whereas, at a room temperature treatment, the color loss was more, as shown in Table 7; this might be due to the unfixed dye molecule on the fabric.
Rubbing fastness was found to be in the range of 4-5 to 5 that indicates that it is in the range of very good to excellent for the dyed cotton fabric.

\section{Assessment of fastness properties of the dyed cotton fabric at $90^{\circ} \mathrm{C} / \mathrm{lh}$}

The Fastness ratings of cotton fabric using silver nanoparticle dyed in different dye concentrations are shown in Table 8. These results indicate the washing fastness of dyed cotton fabrics was good to very good in range. Light fastness was also found to be in the field of good to very good. Rubbing fastness is in the range of $4-5$ to 5 , i.e., very good to excellent for dyed cotton using silver nanoparticles. This indicates that dye fixed through dyeing may be caused by the creation of metal chelates in the presence of tannin which was present to a substantial extent in Sterculia foetida fruit shell extract. The tannins having 
phenolic construction, promote the creation of metal chelate together and silver nanoparticles. Hence, dyed with silver nanoparticles these tannins present in Sterculia foetida fruit shell extract become insoluble in water and improve washing fastness properties.

Table 6 Dyeing of cotton fabric in rota dyer at $90^{\circ} \mathrm{C}$ for Ih before wash

\begin{tabular}{llllll}
\hline Sample & pH & L* & $\mathbf{a}^{*}$ & $\mathbf{b}^{*}$ & K/S \\
\hline Cotton treated with 10\% FSE-AgNPs & 7 & 58.652 & 9.097 & 17.706 & 0.902 \\
Cotton treated with 10\% FSE-AgNPs & 10 & 74.569 & 4.6125 & 16.698 & 2.215 \\
Cotton treated with 50\% FSE-AgNPs & 7 & 70.632 & 4.9582 & 11.515 & 1.125 \\
Cotton treated with 50\% FSE-AgNPs & 10 & 58.261 & 8.214 & 17.877 & 2.3464
\end{tabular}

Table 7 Dyeing of cotton fabric in rota dyer at $90^{\circ} \mathrm{C}$ for Ih after 5 washes

\begin{tabular}{llllll}
\hline Sample & $\mathbf{p H}$ & $\mathbf{L} *$ & $\mathbf{a}^{*}$ & $\mathbf{b} *$ & K/S \\
\hline Cotton treated with 10\% FSE-AgNPs & 7 & 58.864 & 8.463 & 17.804 & 0.7904 \\
Cotton treated with 10\% FSE-AgNPs & 10 & 75.495 & 4.424 & 16.241 & 2.1243 \\
Cotton treated with 50\% FSE-AgNPs & 7 & 70.672 & 4.4138 & 11.218 & 1.0236 \\
Cotton treated with 50\% FSE-AgNPs & 10 & 57.216 & 7.0154 & 15.822 & 2.1734
\end{tabular}

Table 8 Fastness properties of dyed cotton fabric in rota dyer at $90^{\circ} \mathrm{C} / \mathrm{lh}$

\begin{tabular}{llllll}
\hline Dye conc., & pH & Washing fastness & Light fastness & \multicolumn{2}{c}{ Rubbing fastness } \\
\cline { 6 - 7 } \% owf & & & 5 & Dry & Wet \\
\hline Cotton treated with 10\% FSE-AgNPs & 7 & $4-5$ & $5-6$ & 5 & 5 \\
Cotton treated with 10\% FSE-AgNPs & 10 & $4-5$ & $5-6$ & 5 & 5 \\
Cotton treated with 50\% FSE-AgNPs & 7 & 4 & $5-6$ & 5 & $4-5$ \\
Cotton treated with 50 \% FSE-AgNPs & 10 & 4 & 5 & $4-5$ \\
\hline
\end{tabular}

\section{Ultraviolet protective properties}

The Ultraviolet protection factor (UPF) values of the silver nanoparticles treated cotton fabric by the rota dyeing (exhaust) method dyeing and their durability of UV protection efficiency are shown in Table 9. Cotton treated with exhaust process at $90^{\circ} \mathrm{C}$ for $1 \mathrm{~h}$ offered excellent protection from UV radiation as compared to the untreated sample. The UPF values and protection data of the silver nanoparticles treated cotton fabric by rota dyeing showed adequate UV protection in a higher concentration of extract solution, as shown in Table 9.

Table 9 Ultraviolet protection properties for dyed cotton fabric

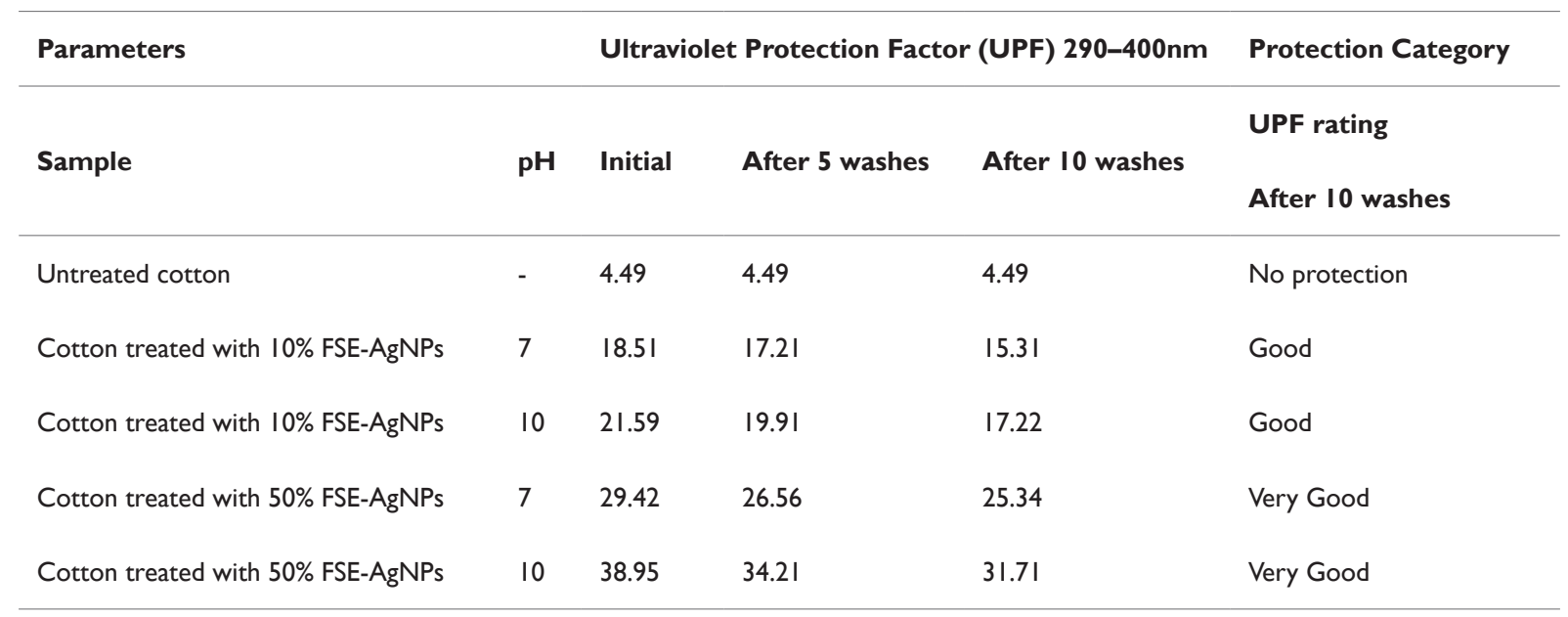


UPF of untreated cotton fabric at 4.49 has no protective abilities and it allows transmission of solar radiation. There is an improvement of the UPF rating of cotton fabric after dyeing with synthesized nanosilver using fruit shell extract both in the case of $\mathrm{pH} 7$ and $\mathrm{pH}$ 10 for $10 \%$ and $50 \%$ FSE concentration. Analysis of results in Table 9 reveals that cotton treated with 50\% FSE-AgNPs at $\mathrm{pH} 10$ showed maximum UPF value in an excellent rating even after ten washes.

Deep dyeing as a result of the existence of tannin also can help to increase the UPF rating. Additionally, the "good to excellent" UPF score after dyeing with Sterculia foetida fruit shell extract might be due to the coated layer on the dyed cotton fabric, which can be seen from the SEM image (Figure 7). EDS analysis also reveals the presence of an elemental peak of magnesium, silicon, phosphorus, calcium, sulphur, chlorine and phosphorus on dyed cotton fabric using fruit shell extract alone also supports the ultraviolet protection of cotton fabric.

\section{Antibacterial test of Sterculia foetida fruit shell extract cotton fabric}

The quantitative analysis of the percentage reduction in gramnegative bacteria was done for cotton using nanosilver dyed with fruit shell extraction, and results are given in Table 10. The results indicate that the dyed fabric using silver nanoparticles inherently showed excellent antibacterial property against E. coli. After five and ten washes, this level of colonies reduction percentage gradually decreased. Compared to S. aureus good results were obtained for E. coli bacteria. As seen in either the concentration after five washes and yet the overall reductions in colony growth were greater than $85 \%$ both for $S$. aureus and E. coli.

The observed antibacterial property of the treated cotton fabric is due to the presence of silver, which is well known and reported in the literature. Moreover, it showed excellent results might be due to the tannins present in fruit shell extract, which was discovered to be $4.71 \%$. These polyphenolic compounds that bind to cellulosic material have been shown to have antibacterial action. The presence of flavonoids, terpenoid, and saponin, was also found to be present in fruit shell extract act as an antibacterial agent against $\mathrm{S}$. aureus and E. coli. The EDS analysis also showed that Sterculia foetida fruit shell extract comprises metal ions like chromium, nickel, magnesium, calcium, potassium along with chlorine and silicone molecules which may be responsible for getting suitable antibacterial property even after ten washes for dyed cotton fabric.

\section{SEM-EDS analysis}

SEM micrograph of untreated and treated cotton fiber is depicted in Figure 7. As exhibited in Figure 7(a), the cotton fiber had a smooth and clear surface free of surface imperfections. After the treatment of the synthesized silver nanoparticles depicted in Figure 7(b) to Figure 7(e) showed the top layer of the material has the residue of the coating. It was found from the $50 \%$ FSE-AgNPs at $\mathrm{pH} 10$ from Figure 7(e) that treated cotton fabric surfaces have more deposition as a coated layer compared to treated with $10 \%$ FSE. A coated layer on the treated cotton might help for good ultraviolet protection and antibacterial properties.

Elemental peaks of Sterculia foetida fruit shell extract using its atomic and weight percentages are reported in Table 11. Sterculia foetida fruit shell extract showed several elemental peaks of carbon, oxygen, magnesium, chromium, chromium, calcium, potassium, sulphur, chlorine and phosphorus. The components within the dried fruit shell extract might be in the form of either metallic oxide or metallic chloride. It has been found that the fruit shell extract along with nano silver particles dyed cotton fabric might also be responsible for the excellent antibacterial and UV protection properties.
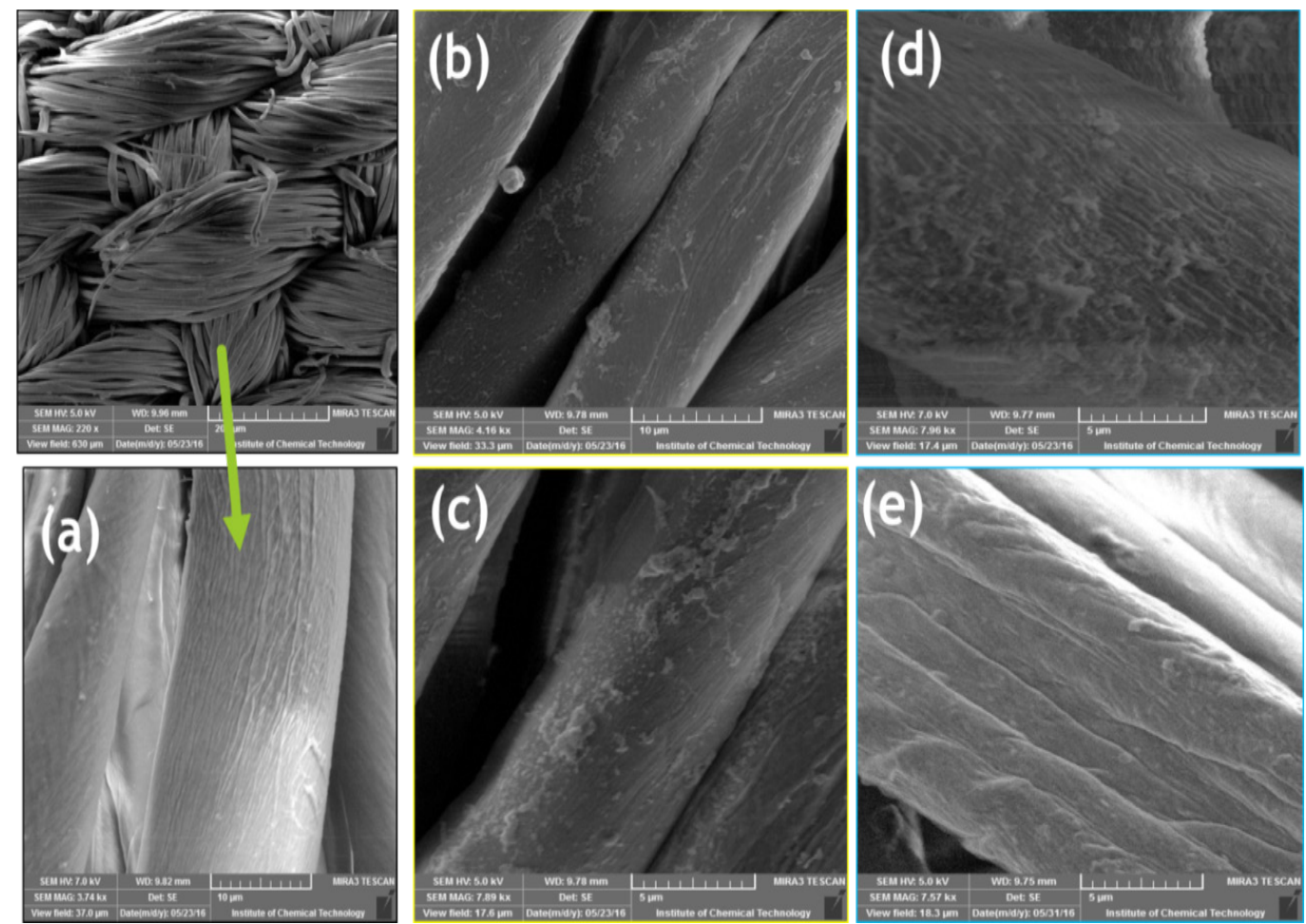

Figure 7 SEM analysis of (a) untreated and treated cotton fabric for (b) $10 \%$ FSE-AgNPs at pH 7 (c) $10 \%$ FSE-AgNPs at pH 10 (d) $50 \%$ FSE-AgNPs at pH 7 (e) $50 \%$ FSE-AgNPs at $\mathrm{pH} 10$. 
Table 10 The antibacterial property of the dyed cotton fabric

\begin{tabular}{|c|c|c|c|c|c|c|c|}
\hline \multirow{2}{*}{$\begin{array}{l}\text { Sample } \\
\text { Rota dyer at } 90^{\circ} \mathrm{C} / \mathrm{lh}\end{array}$} & \multirow[b]{2}{*}{$\mathrm{pH}$} & \multicolumn{2}{|c|}{ Reduction (\%) E. Coli } & \multirow[b]{2}{*}{ After 10 washes } & \multicolumn{2}{|c|}{ Reduction (\%) S.Aureus } & \multirow[b]{2}{*}{ After 10 washes } \\
\hline & & Initial & After 5 washes & & Initial & After 5 washes & \\
\hline Cotton treated with $10 \%$ FSE-AgNPs & 7 & 90.06 & 86.89 & 84.14 & 92.06 & 89.34 & 83.45 \\
\hline Cotton treated with $10 \%$ FSE-AgNPs & 10 & 92.96 & 88.44 & 86.65 & 94.96 & 91.32 & 87.56 \\
\hline Cotton treated with $50 \%$ FSE-AgNPs & 7 & 97.67 & 94.63 & 88.73 & 96.67 & 92.32 & 89.43 \\
\hline Cotton treated with $50 \%$ FSE-AgNPs & 10 & 98.34 & 96.21 & 91.42 & 99.14 & 94.56 & 90.87 \\
\hline
\end{tabular}

Table I I EDS analysis of dried fruit shell extract for quantification of elements

\begin{tabular}{|c|c|c|}
\hline \multirow{2}{*}{$\begin{array}{l}\text { Quantification of elements } \\
\text { Element }\end{array}$} & \multicolumn{2}{|c|}{ Sterculia foetida fruit shell extrac } \\
\hline & Weight (\%) & Atomic (\%) \\
\hline Carbon, C & 21.96 & 33.18 \\
\hline Nitrogen, $\mathrm{N}$ & -- & -- \\
\hline Oxygen, $\mathrm{O}$ & 44.01 & 49.91 \\
\hline Sulphur,S & 0.59 & 0.33 \\
\hline Sodium, $\mathrm{Na}$ & 0.38 & 0.3 \\
\hline Silicon, Si & 0.41 & 0.26 \\
\hline Poshporus, $\mathrm{P}$ & 0.81 & 0.47 \\
\hline Potassium, $\mathrm{K}$ & 26.96 & 12.51 \\
\hline Calcium, $\mathrm{Ca}$ & 1.02 & 0.46 \\
\hline Chlorine, $\mathrm{Cl}$ & 1.32 & 0.67 \\
\hline Magnesium, Mg & 2.54 & 1.9 \\
\hline
\end{tabular}

\section{Conclusion}

The present work demonstrated that Sterculia foetida fruit shell extracts were capable of producing $\mathrm{Ag}^{\circ}$ from an aqueous solution of $\mathrm{Ag}^{+}$. Reduction of silver ion $\left(\mathrm{Ag}^{+}\right)$to metallic silver nanoparticles $\left(\mathrm{Ag}^{\circ}\right)$ was done at room temperature and the minimum sizes of synthesized silver were $15 \mathrm{~nm}$. UV-visible spectroscopy and FTIR characterized the reduced silver nanoparticles. Cotton was dyed with the Sterculia foetida fruit shell extract using synthesized silver nanoparticles. The treated fabric was characterized for $\mathrm{K} / \mathrm{S}$, color fastness to washing, light, and rubbing and the results were found to be very good at $90^{\circ} \mathrm{C}$ for $1 \mathrm{~h}$. Treated cotton fabric using synthesized nanoparticles showed excellent antibacterial and ultraviolet protection properties both at room temperature and at $90^{\circ} \mathrm{C}$ for $1 \mathrm{~h}$. However, after 10 washing fabrics treated in the rota dyeing method at $90^{\circ} \mathrm{C}$ for $1 \mathrm{~h}$ found to achieve very good antibacterial and UV protective properties. Hence, Sterculia foetida fruit shell extract is promising enough to be used as a green reducing agent for the synthesis of nanoparticles with good natural coloration and multi functionalised textile fabrics.

\section{Acknowledgments}

None.

\section{Funding}

None.

\section{Conflicts of interest}

The authors have no conflicts of interest regarding the publication of this paper.

\section{References}

1. Türe H, Gällstedt M, Hedenqvist MS. Antimicrobial compressionmoulded wheat gluten films containing potassium sorbate. Food Res Int. 2012;45:109-115.

2. Iravani S Green synthesis of metal nanoparticles using plants. Green Chem. 2011;13:2638-2650.

3. Malik P, Shankar R, Malik V, et al. Green chemistry based benign routes for nanoparticle synthesis. J Nanoparticles. 2014.

4. Makarov VV, Love AJ, Sinitsyna OV, et al. "Green" nanotechnologies: synthesis of metal nanoparticles using plants. Acta Naturae. 2014.

5. Colson P, Henrist C, Cloots R, Nanosphere lithography: a powerful method for the controlled manufacturing of nanomaterials. J Nanomater. 2013.

6. Jain PK, Huang X, El-Sayed IH, et al. Noble metals on the nanoscale: optical and photothermal properties and some applications in imaging, sensing, biology, and medicine. Acc Chem Res. 2008;41:1578-1586.

7. Vigneshwaran N, Ashtaputre NM, Varadarajan PV, et al. Biological synthesis of silver nanoparticles using the fungus Aspergillus flavus. Mater Lett. 2007;61:1413-1418. 
8. Frattini A, Pellegri N, Nicastro D, et al. Effect of amine groups in the synthesis of $\mathrm{Ag}$ nanoparticles using aminosilanes. Mater Chem Phys. 2005;94:148-152.

9. Navaladian S, Viswanathan B, Viswanath RP, et al. Thermal decomposition as route for silver nanoparticles. Nanoscale Res Lett. 2007;2:44.

10. Klaus T, Joerger R, Olsson E, et al. Silver-based crystalline nanoparticles, microbially fabricated. Proc Natl Acad Sci. 1999;96:13611-13614.

11. Gupta B, Tummalapalli M, Deopura BL, et al. Preparation and characterization of in-situ crosslinked pectin-gelatin hydrogels. Carbohydr Polym.2014;106:312-318.

12. Haldar KM, Haldar B, Chandra G. Fabrication, characterization and mosquito larvicidal bioassay of silver nanoparticles synthesized from aqueous fruit extract of putranjiva, Drypetes roxburghii (Wall.). Parasito Res. 2013;112:1451-1459.

13. Maheswari RU, Lakshmi Prabha AL, Nandagopalan V, et al. Synthesis of silver nanoparticles by using fruit extract of Dioscorea oppositifolia L. $J$ Res Nanobiotechnology. 2012;1:9-13.

14. Teli MD, Pandit P. Application of Sterculia foetida fruit shell waste biomolecules on silk for aesthetic and wellness properties. Fibers and Polymers. 2018;19:41-54.

15. Suganya J, Viswanathan $\mathrm{T}$, Radha $\mathrm{M}$, et al. Comparative quantitative screening of secondary phytoconstituents from the leaves extract of Sterculia foetida Linn. Res J Pharm Technol. 2017;10:2907-2912.
16. Teli MD, Pandit P. A novel natural source Sterculia foetida fruit shell waste as colorant and ultraviolet protection for linen. Journal of Natural Fibers. 2018;15:337-343.

17. Pandit P, Gayatri TN, Maiti S. Green and sustainable textile materials using natural resources, green and sustainable advanced materials: processing and characterization. 2018:213-261.

18. Pandit P, Jose S, Pandey R. Groundnut testa: an industrial agro-processing residue for the coloring and protective finishing of cotton fabric. Waste and Biomass Valorization. 2020:1-12.

19. Pandit P, Gayatri TN. Characterization of green and sustainable advanced materials. Green Sustain Adv Mater Process Charact. 2018:35-66.

20. Teli MD, Sahoo MR, Pandit P. Antibacterial and UV-Protective Cotton fabric made by Herbal Synthesized Silver Nanoparticles. Int Res J Eng Technol. 2017;4:1310-1321

21. Iravani S, Korbekandi H, Mirmohammadi SV, et al. Synthesis of silver nanoparticles: chemical, physical and biological methods. Res Pharm Sci. 2014;9:385.

22. Ponarulselvam S, Panneerselvam C, Murugan K, et al. Synthesis of silver nanoparticles using leaves of Catharanthus roseus Linn. G. Don and their antiplasmodial activities. Asian Pac J Trop Biomed. 2012;2:574-580.

23. Yi Z, Li X, Xu X, Bet al.. Tang, Green, effective chemical route for the synthesis of silver nanoplates in tannic acid aqueous solution. Colloids Surfaces A Physicochem En Asp. 2011;392:131-136. 